\title{
El problema formas/vida y el estructuralismo vitalista de Jakob von Uexküll
}

\author{
The problem between forms and life and vitalist structuralism of Jakob \\ von Uexküll
}

\author{
Juan Manuel Heredia*
}

\begin{abstract}
Resumen: Este artículo analiza el sentido histórico-conceptual que asume la teoría de Jacob von Uexküll sobre el fondo del problema formas/vida que se despliega en la filosofía continental de principios del siglo XX. Para ello, en primer lugar, reconstruye la configuración epistemológica que presenta el pensamiento biológico entre 18901920, e introduce las tesis neovitalistas de Hans Driesch. En segundo lugar, analiza la emergencia de las metafísicas vitalistas de Henri Bergson y de Georg Simmel, y plantea el problema de la contradicción entre las formas y la vida. Por último, y sobre la base de dichos desarrollos, defiende la tesis según la cual la obra de Uexküll moviliza un estructuralismo vitalista para el cual "Vida igual a Forma".
\end{abstract}

Palabras clave: Jakob von Uexküll; Problema formas/vida; Vitalismo; Estructuralismo vitalista; Filosofía del siglo XX.

Abstract: This paper analyzes the historical-conceptual sense that Jacob von Uexküll's theory assumes in contrast with the forms/life problem that unfolds in the continental philosophy of the beginning of the 20th century. For this purpose, in first place, it reconstructs the epistemological configuration that presents the biological thought between 1890-1920 and introduces the neovitalist theory of Hans Driesch. Secondly, it analyses the emergence of the vitalist metaphysics of Henri Bergson and Georg Simmel and poses the problem of the contradiction between forms and life. Finally,

\footnotetext{
* Licenciado y Doctor en Filosofía por la Universidad de Buenos Aires. Es becario posdoctoral del Consejo Nacional de Investigaciones Científicas y Técnicas (CONICET), con lugar de trabajo en el Centro de Historia Intelectual de la Universidad Nacional de Quilmes. Ha publicado capítulos de libro y artículos académicos sobre las teorías de Gilbert Simondon, Jakob von Uexküll y Gilles Deleuze, entre otros, centrando su investigación en la filosofía contemporánea. Dirección electrónica: herediajuanmanuel@gmail.com
} 
on the basis of the previous developments, it defends the thesis according to which Uexküll's work mobilizes a vitalist structuralism for which "Life equal to Form".

Key words: Jakob von Uexküll; Forms/life problem; Vitalism; Vitalist structuralism; 20th Century Philosophy.

\section{Introducción}

La biología teórica de Jakob von Uexküll (1864-1944) ocupa un lugar destacado en el pensamiento del siglo XX. Por un lado, las referencias a su obra resultan significativas, transgreden distintas fronteras (espaciotemporales, disciplinares, de tradiciones reflexivas) y no resultan anecdóticas. Sus conceptos son valorados positivamente por filósofos tan diversos como Cassirer, Scheler, Heidegger, Ortega y Gasset, Canguilhem, Merleau-Ponty, Simondon, Deleuze, Agamben, Sloterdijk, entre otros, y el impacto de su enfoque se registra en la antropología (H. Plessner, A. Gehlen), la etología (K. Lorenz), la psicología (K. Goldstein, J. Lacan), la teoría general de los sistemas (L. von Bertalanffy), la ecología (P. W. Zapffe, A. Næs) y, desde la década del ochenta, en la biosemiótica (T. Sebeok, K. Kull, C. Emmeche, C. Brentari). Asimismo, a nivel histórico-intelectual, la teoría uexkülliana resulta un índice fructífero pues permite tematizar e iluminar una serie de transformaciones conceptuales relevantes acaecidas en la primera parte del siglo XX, como ser la recuperación de la filosofía kantiana, la crisis del evolucionismo decimonónico y el debate metafísico-biológico en torno a la noción de vida, la introducción de la idea de mundo circundante y su impacto en la antropología filosófica alemana en 192030, la génesis de enfoques estructurales y sistémicos, la emergencia de la etología y las teorías del comportamiento, etc. En todos esos procesos, los conceptos de Uexküll y las problemáticas que ellos alumbran, destacan con singular relevancia.

Esta centralidad, y sus múltiples ramificaciones filosóficas, es actualmente objeto de un creciente reconocimiento. Síntoma de ello es que, en las últimas décadas, han aumentado los papers y los artículos que lo tienen como protagonista, han surgido estudios enteramente dedicados al tratamiento de su obra (Mildenberger, 2007; Buchanan, 2008; Castro García, 2009; Brentari, 2015), y algunos de sus libros han sido reeditados y traducidos en Francia, Estados Unidos y Argentina. Del conjunto de esta literatura se desprenden tres 
abordajes predominantes. Por un lado, estudios sobre la relación de Uexküll con la semiótica y la biosemiótica (Kull, Emmeche, Hoffmeyer et al., 2009; Brentari, 2013, 2015; Guidetti, 2013; Araújo, 2016). Por otro lado, encontramos textos biográficos, introductorios y/o histórico-intelectuales (Harrington, 1996; Kull, 2001, 2004; Rüting, 2004; Mildenberger, 2007). Por último, destacan múltiples trabajos centrados en analizar la influencia de su teoría biológica en determinados filósofos y tematizar, así, la recepción de sus conceptos. En este punto, se registran ensayos sobre su impacto en Heidegger (Agamben, 2006; Muñoz Pérez, 2015; Alsina Calvés, 2018), Cassirer (Krois, 2004; Chien, 2006; Stjernfelt, 2009) Ortega y Gasset (Olivé Pérez, 2018), Merleau-Ponty (Buchanan, 2008; Ostachuk, 2013; Bacarlett Pérez, 2014) y Deleuze (Buchanan, 2008), entre otros.

En general, en este conjunto de lecturas el centro de gravedad de los análisis anida en el concepto uexkülliano de Umwelt (mundo circundante). Si bien la atracción hacia esta idea tiene sus fundamentos, pues quizá se trate de la principal innovación nocional del autor, creemos que la significación filosófica e histórico-intelectual de la teoría de Uexküll no se agota en ella. Este trabajo busca ser un aporte en este sentido, y aspira a iluminar un aspecto poco frecuentado de su pensamiento. Nuestra intención es pensar el sentido que asume la apuesta teórico-metodológica uexkülliana en el marco del problema formas/vida que se despliega en las filosofías vitalistas de las primeras décadas del siglo XX. Para ello, en primer término, reconstruiremos el estado de situación de las ciencias de la vida del período y analizaremos en dicho contexto la emergencia de las metafísicas de H. Driesch, H. Bergson y de G. Simmel. En segundo lugar, tras explicitar el problema formas/vida que se desprende de dichas filosofías, sostendremos la tesis según la cual el proyecto teórico uexkülliano moviliza un estructuralismo vitalista que se afirma en la ecuación "Vida igual a Forma". ${ }^{1}$

\section{El conflicto entre las formas y la vida}

El problema filosófico de la antinomia entre las formas y la vida emerge en un suelo histórico-intelectual particular. Su formulación sintética se la debemos a Simmel, pero las premisas sobre las cuales se asienta permean a buena parte del

\footnotetext{
${ }^{1}$ Uexküll, Jacob von, Teoría de la vida, Madrid, Summa, 1944, p. 50.
} 
pensamiento filosófico de inicios del siglo XX y se relacionan, en el período que va de 1890 a 1920, con un proceso de transformación de los esquemas epistemológicos. Ernst Cassirer percibe tempranamente los contornos de este desplazamiento histórico-epistemológico, señala el enorme crecimiento que asume desde fines del siglo XIX la categoría de totalidad en diversos dominios de investigación científica (física, biología, psicología, lingüística, etc.), e indica dos consecuencias: por un lado, que dicha categoría (liberada de sus connotaciones teleológicas) adquiere rasgos sincrónicos y estructurales, neutralizando así las premisas historicistas-evolucionistas decimonónicas; por el otro, que a la luz de ciertos descubrimientos científicos, hay que hacerse a la idea de que la naturaleza hace saltos, que hay mutaciones y discontinuidades difícilmente explicables mediante esquemas causales o teleológicos de sucesión ordenada. ${ }^{2}$ Ambas consecuencias se refuerzan recíprocamente y se cifran en la idea de forma. ${ }^{3}$

La centralidad que esta categoría inter-científica asume progresivamente en el plano del objeto, contrasta con la emergencia de filosofías que tematizan desde un horizonte metafísico el problema de la génesis y transformación de las formas. Como demuestra Elías Palti (2003), este proceso se expresa en un cambio de estatuto en el plano del sujeto: éste dejará de ser aquel que garantiza la realización del orden en la historia y pasará a ser aquel que altera, desde afuera, la lógica de auto-reproducción de los sistemas formales. ${ }^{4}$ Se despliega, así, en la primera parte del siglo XX, una oposición correlativa entre cambio y

2 Cassirer, Ernst, Las ciencias de la cultura, México, Fondo de Cultura Económica, 1975, pp. 139-145, 152-153.

3 Según nuestro análisis, la categoría de forma asume cuatro características: (1) una forma es una totalidad sincrónica cerrada que compromete una pluralidad de elementos, fuerzas y/o funciones interrelacionadas; (2) las formas tienden al equilibrio, a la autorregulación y a la homeostasis, es decir, a la preservación de su coherencia y balance interno; (3) las formas no se explican en función de su pasado ni de su tendencia a cierto porvenir, sino conforme su configuración actual y la estructura que tienden a reproducir; (4) las formas tienen una realidad de orden teórico y un carácter meta-fenoménico, es decir, instituyen un segundo orden de objetividad que tematiza estructuras, sistemas, modelos físico-matemáticos, unidades funcionales, y no sustancias, procesos empíricos o relaciones de causalidad.

4 Palti, Elías José, “El 'retorno del sujeto'. Subjetividad, historia y contingencia en el pensamiento moderno", Prismas. Revista de bistoria intelectual, 7 (2003), pp. 35-36. 
orden, entre vida y formas, entre sujeto y estructura, que era impensable en el sistema de pensamiento decimonónico.

En el campo de las ciencias de la vida esta situación se manifiesta en una crisis del pensamiento evolucionista y, correlativamente, en la emergencia de las tesis neovitalistas. Julian Huxley denomina "el eclipse del darwinismo"5 al período 1890-1930, indicando con ello el surgimiento de una serie de hechos científicos contrarios a las premisas sobre las cuales se organizaba la explicación filogenética del siglo XIX. Con la postulación de la idea de plasma germinal a manos de August Weismann en 1892-1893, y la división tajante entre células somáticas y células germinales, se refuta la teoría de la herencia de los caracteres adquiridos y el criterio de uso/desuso de los órganos, elementos introducidos por Lamarck y aún presentes en el esquema darwinista de 1859. Esta idea de una continuidad del plasma germinal, y la independencia que suponía con respecto a los avatares empíricos (e históricos) de los vivientes, replantea sobre nuevas bases el problema de la herencia. Este problema encuentra en las tesis mutacionistas (Hugo De Vries) y saltacionistas (William Bateson) una resolución sorprendente: las nuevas formas específicas no surgirían por un proceso gradual de acumulación de diferencias, sino mediante un cambio brusco.

Este concepto moviliza una profunda crítica de los enfoques genealógicos y de los esquemas evolucionistas decimonónicos, y dará lugar a una situación paradójica en la cual cabe pensar la génesis de las especies a partir de mutaciones súbitas y discontinuas de carácter contingente; saltos que pueden ser corroborados y puestos de manifiesto pero que resultan inexplicables en términos causales o teleológicos. En este contexto, la génesis y transformación de las especies deviene totalmente enigmática, habilitando la introducción de teorías metafísicas y llevando a Uexküll, por ejemplo, a señalar: "¿Cómo se origina el individuo? Es la cuestión que se apodera de la ciencia natural después de que el problema del origen de las especies se le ha escapado como insoluble". 6

\footnotetext{
${ }^{5}$ Huxley, Julian, Evolution: The Modern Synthesis, London, George Allen and Unwin, 1948, pp. 22-28.

${ }^{6}$ Uexküll, Jacob von, Ideas para una concepción biológica del mundo, Buenos Aires, EspasaCalpe, 1951, p. 27.
} 
Esta remisión a la ontogénesis nos permite comprender el renacimiento de las tesis vitalistas en biología, proceso acicateado por los estudios de regulación y regeneración de los organismos. Gustav Wolf demuestra en 1890 que un tritón puede, tras una mutilación del cristalino de un ojo, regenerar perfectamente el órgano dañado y hacerlo valiéndose de tejidos diferentes a los empleados en su desarrollo embriológico. Ello lo conduce a afirmar la existencia en los organismos de un principio teleológico originario que sería inexplicable en términos evolucionistas. Estos estudios rehabilitaron la perspectiva embriológica y ontogenética introducida por K. E. von Baer a principios del siglo XIX (la cual fuera opacada por los enfoques filogenéticos evolucionistas de la segunda parte de dicho siglo), y reintrodujeron el problema de la teleología en la biología teórica. En este marco emergen, entre 1899 y 1905, las tesis neovitalistas de Hans Driesch, quien realiza el siguiente experimento: corta en dos el embrión de un erizo de mar y constata que, lejos de producirse una división de la estructura orgánica o estropearse el proceso embriológico, nacen de cada parte dos erizos de mar perfectos, aunque de la mitad de su tamaño. De allí, concluye la existencia de un principio vital ("entelequia" o "psicoide") que no sólo sería irreductible a los factores físicoquímicos, sino que los dirigiría siendo un agente no mecánico.

Este agente vital, según Driesch, no ocupa lugar en el espacio y su naturaleza no es material ni energética. ¿Cuál es su definición positiva? Se trata de una cuasi-razón suficiente, de una "causalidad individualizante y unificante" que debe ser vista como "el prototipo del devenir biológico"7 pues, sin ella, dicho devenir resultaría inexplicable. ¿Cómo opera este agente individualizante en la ontogénesis? O bien suspende el despliegue de las actividades físicoquímicas o bien relaja esa suspensión, y Driesch agrega "la entelequia es un agente sui generis, no-material y no-espacial pero que actúa, por así decirlo, 'en el' espacio", es decir, es un agente inmaterial capaz de "alterar la dirección de las partículas materiales y, por esta acción, también de alterar la dirección de sus fuerzas". ${ }^{8}$

Si bien para Driesch este agente vital es una idea lógico-metafísica y, en última instancia, resulta incognoscible, indica que hay al menos tres fenómenos

\footnotetext{
${ }^{7}$ Driesch, Hans, The history and theory of vitalism, London, MacMillan and Co, 1914, p. 201.

${ }^{8}$ Ibid., p. 204.
} 
que justifican la postulación de su existencia. El primero es la embriología experimental. El autor evoca los experimentos de Gustav Wolf, y los suyos, para señalar que los animales y sus partes son "sistemas armónicosequipotenciales". Tomando como ejemplo el poder de regeneración de los erizos de mar, Driesch afirma que "son equipotenciales porque cada uno de sus elementos (las células) poseen evidentemente las mismas 'potencias' morfogenéticas", 9 y son armónicos porque dichos elementos trabajan juntos y coordinadamente, pues de lo contrario el resultado de la regeneración total sería inexplicable. La segunda "prueba del neovitalismo" es el proceso embriológico mismo, donde una célula germinal se divide y subdivide progresivamente en la formación del organismo. Ante ello, Driesch se pregunta retóricamente “¿Cómo podría una máquina ser dividida innumerables veces y seguir siendo lo que era [antes de las divisiones]?”. ${ }^{10}$ Como tercera prueba, plantea que los esquemas causales son incapaces de explicar los modos de actuar de los organismos, y las condiciones que los hacen posibles (entre ellas, la posesión de algún tipo de memoria o "base histórica de reacción"). ${ }^{11}$ Con estos indicios experimentales, Driesch instala el enfoque neovitalista y, mediante las nociones de causalidad individualizante y unificante, sistema armónico-equipotencial y devenir vital, reivindica la especificidad de la vida frente a la materia, fundando una perspectiva que denomina "teleología dinámica".

Recortándose sobre el fondo histórico-conceptual reseñado, en 1907 Henri Bergson publica La evolución creadora, donde recapitula las principales aporías que afectan al pensamiento biológico del período e introduce, en contraste con ellas, su idea metafísica de vida. Apelando a una intuición intelectual de orden psicológico (y de tintes schellingianos), Bergson construye su noción de vida a partir de sus reflexiones sobre la memoria y la duración real, pero la enriquece atendiendo a problemáticas específicas de las ciencias naturales. Respecto de esto último, destacan algunas operaciones conceptuales. En principio, apoyándose en la embriología experimental de Wolf y Driesch, Bergson suscribe que los cuerpos vivos son irreductibles a los esquemas analítico-mecanicistas y reconoce que hay en la vida una búsqueda de individualidad. No obstante, lo que le interesa subrayar no es la existencia de

\footnotetext{
${ }^{9}$ Ibid., pp. 208-209.

10 Ibid., pp. 211-212.

11 Ibid., pp. 212-213.
} 
una causalidad individualizante, sino la continuidad de un impulso profundo e interno responsable de la creación de diversas formas de vida, y frente al cual los individuos vivientes aparecen como "accidentes" discontinuos. Para ello plantea dos argumentos, el primero remite a su teoría de la duración real: "Donde quiera que algo vive hay, en algún sitio, un registro abierto en el que se inscribe el tiempo", "la evolución implica una continuación real del pasado en el presente, una duración que es un trazo de unión". ${ }^{12}$ Esta idea de un flujo indiviso se apoya en un segundo argumento que el filósofo francés deriva explícitamente de la teoría de la continuidad del plasma germinal de Weismann: "la vida se manifiesta como una corriente que va de un germen a otro germen por mediación de un organismo desarrollado". ${ }^{13}$

Respecto de la fuente de las variaciones, Bergson repasa dos hipótesis de variación accidental: la variación insensible (que adjudica al darwinismo) y la brusca (que remite a De Vries y Bateson). Contra la primera, aborda el ejemplo de un órgano como el ojo (sumamente complejo en estructura y eminentemente simple en su función) y, contrastando la similitud de estructura que presentan los ojos de los vertebrados y los de moluscos, se pregunta “¿cómo suponer que las mismas pequeñas variaciones, en número incalculable, se hayan producido en el mismo orden en dos líneas de evolución independientes, si fuesen meramente accidentales?". ${ }^{14}$ Frente a la teoría de las mutaciones señala que, si bien economiza la multitud de variaciones azarosas que han de converger, presenta otro problema relativo al funcionamiento simple del órgano en cuestión: “¿cómo es que todas las partes del aparato visual, al modificarse de pronto, siguen tan bien coordinadas entre sí que el ojo continúa ejerciendo su función?”. 15 Tras problematizar la insuficiencia de las hipótesis de la variación accidental, y en el contexto del eclipse del darwinismo, Bergson avanza en la construcción de su metafísica vitalista mediante una rectificación del finalismo y sobre la base de dos consignas: "la tendencia a cambiar no es accidental", "O el tiempo es invención o no es absolutamente nada". ${ }^{16}$

\footnotetext{
${ }^{12}$ Henri Bergson, La evolución creadora, Barcelona, Planeta, 1985, pp. 28, 33.

13 Ibid., p. 36.

14 Ibid., p. 68.

15 Ibid., p. 69.

${ }^{16}$ Ibid., pp. 86, 296.
} 
Respecto del ejemplo del ojo, afirma que ante problemas comunes las soluciones tienden a ser similares, y el ojo es la respuesta creativa de la vida ante el problema planteado por la luz. Así, en líneas de evolución heterogéneas e independientes, es posible que se creen órganos de percepción cuasiidénticos, pues "es concebible que el mismo esfuerzo para sacar provecho de las mismas circunstancias llegue al mismo resultado, sobre todo si el problema planteado por las circunstancias exteriores es de los que no admiten más que una solución". ${ }^{17}$ Esta evolución a fuerza de resolver problemas nos permite abordar su crítica al neolamarckismo y al neovitalismo de Driesch. Bergson señala que la posición de este último "se hace muy difícil por el hecho de que en la naturaleza no hay ni finalidad meramente interna ni individualidad marcada de modo absoluto", y agrega "si hay finalidad en el mundo de la vida, abarca la vida entera en un único e indivisible abrazo". ${ }^{18}$ Contrariamente a lo que afirma Kant en su Crítica del juicio teleológico, para Bergson la única finalidad que cuenta es la externa, y por ello hay que entender -fundamentalmente- la dinámica creativa de resolución de problemas antes aludida. A los neolamarckianos, por último, les reprocha creer que el esfuerzo vital es de orden individual cuando, en realidad, se trataría de un impulso más profundo, de una perseverancia de orden preindividual.

Desde este horizonte, Bergson sostiene que la vida es -como el tiempocreación, invención, cambio, libertad y que, en su evolución, avanza introduciendo indeterminación en la materia, y se pluraliza bifurcando su impulso en función de divergencias, encrucijadas y resolución de problemas. Pero, correlativamente, afirma que a través de la continuidad de una "memoria orgánica", la vida se mantiene una en su multiplicidad. Con esta estrategia, Bergson articula en su concepto dos elementos en principio antagónicos, la creación y la continuidad.

Ahora bien, ¿cómo explica la relación entre la vida y las formas? En principio, afirma programáticamente: "la forma pertenece a lo inmóvil, y la realidad es movimiento. Lo que es real es el cambio continuo de forma; la forma no es más que una instantánea tomada sobre una transición". ${ }^{19}$ En este sentido, Bergson redefine la relación entre orden y cambio, haciendo del segundo de los términos

\footnotetext{
${ }^{17}$ Ibid., p. 79.

${ }^{18}$ Ibid., pp. 49, 50.

${ }^{19}$ Ibid., p. 264.
} 
el objeto de la metafísica e invirtiendo, con ello, una añeja tradición filosófica en la cual el devenir y el cambio residían en la realidad sensible, y el orden en una realidad subyacente, estable e inteligible. Se plantea, entonces, una división del trabajo entre ciencia y metafísica: a la primera le corresponde analizar lo estable y/o reversible (la materia, lo mecánico, las formas objetivadas, lo automático), a la segunda le cabe captar -mediante una intuición intelectualaquella movilidad irreversible y subterránea que explicaría la emergencia de lo nuevo (la memoria, la duración real, la vida, lo voluntario). En este marco, Bergson deja planteada una tensión problemática entre la vida y las formas:

Ese contraste entre la vida en general y las formas en que ésta se manifiesta, presenta siempre el mismo carácter. Podría decirse que la vida tiende a actuar lo más posible, pero que cada especie prefiere aportar la menor cantidad posible de esfuerzo (...) Así, el acto mediante el cual la vida se encamina a la creación de una forma nueva, y el acto por el que esa forma se dibuja, son dos movimientos diferentes y, a menudo, antagónicos. El primero se prolonga en el segundo, pero no puede prolongarse sin distraerse de su dirección. ${ }^{20}$

Georg Simmel prolongará este vitalismo filosófico, y repensará el problema entre la vida y las formas desde un horizonte histórico-cultural. Contrastando con el optimismo bergsoniano, el filósofo y sociólogo alemán le imprimirá un giro trágico al problema. En un artículo de 1916, retomando las tesis que presenta en Philosophische Kultur (1911), Simmel plantea la cuestión en los siguientes términos:

Entre la vida que siempre sigue agitándose en oleadas, que se extiende como una energía que salta a la vista, y las formas de su exteriorización histórica que se mantienen fijas en rígida igualdad, existe inevitablemente un conflicto que llena toda la historia de la cultura (...) La vida creadora produce constantemente algo que no es de nuevo vida, algo en lo que de algún modo se precipita hacia la muerte, algo que le contrapone un título legal propio. La vida no se puede expresar a no ser en formas que son y significan algo

${ }^{20}$ Ibid., pp. 122-123. 
por sí, independientemente de ella. Esta contradicción es la auténtica y continua tragedia de la cultura. ${ }^{21}$

La afirmación simmeliana es cruda y su carácter trágico se cifra en la idea según la cual todo lo que hoy libera, mañana oprime. En uno de sus últimos libros, publicado tres meses después de su muerte, Simmel aborda en términos metafísicos la antinomia entre las formas y la vida, y plantea que la tragedia de la cultura encuentra su origen en una contradicción más profunda entre vida e individualidad. Como señala Jankélévitch, a diferencia de Bergson, para Simmel el problema comenzó el "día en que la corriente continua de la vida se fijó en individualidades cerradas y perecederas". ${ }^{22}$ Con este movimiento, Simmel cambia el eje de la reflexión vitalista: los individuos no son accidentes discontinuos de una continuidad más profunda, tampoco portadores de una inmaterial causalidad individualizante, están habitados por una incomodidad esencial que remite a "una última problemática metafísica de la vida: que ésta es una continuidad sin límites y al propio tiempo un yo determinado por límites". ${ }^{23}$

Simmel reconoce que la vida no puede existir sino es dentro de una forma. Y afirma que es imposible que se manifieste en bruto, como una pura fuerza de exteriorización sin articulación alguna, pero su concepto se encuentra claramente abocado a subrayar su otra característica, a saber, que la vida es auto-trascendente y que todo lo que crea en el plano del espíritu está ahí para ser rebasado. A la vida le es inmanente la tendencia a la trascendencia. Hay momentos en que la vida armoniza con la forma, por ejemplo, con las grandes creaciones artísticas. Pero esos momentos son fenómenos transitorios y, más temprano o más tarde, lentamente o de golpe, la vida rompe las formas de su manifestación expresiva. Asimismo, según Simmel, el carácter autotrascendente de la vida no sólo se manifiesta en el plano del espíritu, sino también en el biológico y fisiológico, porque la vida individual se trasciende a sí misma en la procreación y en la muerte.

21 Simmel, Georg, El individuo y la libertad. Ensayos de crítica de la cultura, Barcelona, Península, 1998, pp. 133-134.

${ }^{22}$ Jankélévitch, Vladimir, Georg Simmel, filósofo de la vida, Barcelona, Gedisa, 2007, p. 83.

${ }^{23}$ Simmel, Georg, Intuición de la vida. Cuatro capitulos de metafísica, La Plata, Caronte, 2004, p. 34. 
Simmel comparte con Bergson el pensar a la vida como esencialmente vinculada a la temporalidad, pero su interés no apunta a pensar una continuidad que se extendería del pasado hacia el presente, sino que se enfoca en el resbalar del presente hacia el futuro, en el hecho de que "la configuración esencial de la vida significa un constante ir más allá de sí misma como presente". ${ }^{44}$ Por otro lado, en relación al espacio, Simmel cita -sin especificar la fuente- a "un biólogo sumamente profundo" para mostrar cómo el desplazamiento de los límites visuales, con instrumentos como los telescopios y microscopios, ha ensanchado en millones de kilómetros el mundo perceptible de los seres humanos. Más allá del hecho de que es altamente probable que el biólogo citado sea Uexküll, Simmel plantea que dicho ejemplo demuestra que "en ciertas direcciones hemos rebasado los contornos de nuestro ser natural" y agrega "tenemos ahora en derredor nuestro un mundo que, si nos pensamos a nosotros mismos como seres de algún modo unitarios (...), ya no es el "nuestro"'. ${ }^{25}$ Este vivir adentro y afuera de los límites, este simultáneo estar formado y trascender la forma, indica "el acto unitario de la vida", esto es, "el estar-limitada y el rebasar el límite". ${ }^{26}$

El argumento de Simmel apunta a mostrar como característica esencial de la vida no solo la temporalidad inmanente, sino también el franqueamiento y la transgresión de los límites que hacen a la relación con el mundo exterior. Y la superación de los límites, ejemplificada con la ruptura de las condiciones de la percepción natural, se manifiesta en todas las esferas de la vida espiritual (el arte, el conocimiento, la religión y la filosofía). En este sentido, la incomodidad de la vida en su forma remite al carácter ambivalente que asume la vida al devenir espiritual, es decir, al repartirse en distintas esferas autónomas de la cultura y cristalizarse en "existencias transvitales" (transvitale Sonderexistezen).

Desde este horizonte, Simmel concluye que la vida comporta dos definiciones complementarias, es "más-vida" (Mehr-Leben) y "más-que-vida" (Mehr-Als-Leben). Es "más-vida" porque es auto-trascendente, porque es transformadora, porque tiende a rebasar sus límites, porque -ya a nivel fisiológico- "es una continua producción nueva" e, incluso, porque también la

\footnotetext{
${ }^{24}$ Ibid., p. 35.

${ }^{25}$ Ibid., pp. 28-29.

26 Ibid., p. 28.
} 
muerte es "un ir de la vida más allá de sí misma". ${ }^{27}$ Es "más-que-vida" porque "en el plano del espíritu es inmanente a la vida la producción de un contenido significativo autónomo". ${ }^{28}$ Y la autonomía de lo creado, el hecho de que las formas se desentiendan de su creador y tiendan a mantener su coherencia, a reproducir su lógica y a reivindicar su significación, con independencia del proceso auto-trascendente de la vida, conduce a "la tragedia del espíritu en general: que la vida se lastima a menudo con los productos rígidamente objetivos que extrajo de sí misma". ${ }^{29}$

\section{El estructuralismo vitalista de Jakob von Uexküll}

El carácter estructural del proyecto teórico-metodológico uexkülliano ha sido valorado por Cassirer ${ }^{30}$ y reconocido por Bertalanffy ${ }^{31}$, entre otros autores. El sentido de su vitalismo, sin embargo, no ha sido objeto de tematización atenta y, más bien, se ha tendido a verlo como un retorno a viejos motivos teleológicos o a diluirlo en la perspectiva del neovitalismo drieschiano. Ciertamente, Uexküll reivindica la embriología de Baer y elogia en no pocos pasajes a Driesch, considerándolos compañeros de batalla en la lucha por defender la autonomía de los fenómenos vitales frente a las reducciones físicoquímicas y los esquemas materialistas-mecanicistas. No obstante, no hay que asimilar el vitalismo uexkülliano a dichas tentativas, pues por ese camino se pierde su singularidad. Uexküll no ofrece ninguna definición sustantiva o sustancial de la vida y, en línea con el espíritu crítico de Kant, plantea que la vida en sí es algo incognoscible. Ya en 1912 afirma "lo que es la vida no lo sabe ninguno de nosotros"32, y en 1930 inicia un libro, que lleva como sugerente título Teoría de la vida, con el siguiente párrafo:

\footnotetext{
${ }^{27}$ Ibid., p. 40.

28 Ibid., p. 43.

${ }^{29}$ Ibid., pp. 99-100.

${ }^{30}$ Cassirer, Ernst, Elproblema del conocimiento IV, México, Fondo de Cultura Económica, 1998, pp. 242-262.

31 Bertalanffy, Ludwig von, Teoría general de los sistemas, México, Fondo de Cultura Económica, 1989, pp. 239-256.

32 Jacob von Uexküll, Ideas para una concepción biológica del mundo, p. 51.
} 
La palabra 'Biología' se presta a ser interpretada erróneamente, si por ella entendemos el estudio o doctrina de la vida. Sucede con la vida lo mismo que con la gravedad. Ambos son fenómenos primarios. De la gravedad lo ignoramos todo. Nuestro conocimiento se limita a algunas particularidades correspondientes a los cuerpos pesados. Lo mismo sucede con la vida. No sabemos nada de ella. Nuestro conocimiento se limita a algunas particularidades relativas a los seres vivos. El estudio de los seres vivos es una ciencia natural pura con un único objeto: la investigación de los tipos de estructura del ser vivo, su origen y su función. ${ }^{33}$

Este tipo de argumentación, consistente en trazar analogías con fenómenos físicos, está lejos de ser original y es un típico recurso de la tradición vitalista. Cosas similares se encuentran en Casper Friedrich Wolff, en Albretch von Haller y en Johann Friedrich Blumenbach. ${ }^{34} \mathrm{Y}$ esta apelación a la máxima newtoniana Hypotheses non fingo, no sólo contribuye a prestigiar indirectamente a la biología con los logros de la física y a trazar una línea preliminar entre ciencia y metafísica, sino que se esgrime, fundamentalmente, para justificar la validez de las observaciones experimentales biológicas (y, con ellas, para cuestionar el reduccionismo de los esquemas mecanicistas). Uexküll asume completamente este punto de partida metodológico: la vida es a la biología lo que la gravedad es a la física, esto es, un fenómeno primario que hay que investigar por sus efectos y no por su causa. ¿Cuál ha de ser, entonces, la idea regulativa o la noción heurística que ha de guiar la observación de los fenómenos biológicos? En casi toda su obra Uexküll responde: la conformidad a plan (Planmäßigkeit). Y este principio teórico-metodológico no asume en él un sentido meramente epistemológico, sino también ético y político. ${ }^{35}$

\footnotetext{
${ }^{33}$ Jacob von Uexküll, Teoría de la vida, p. 9.

34 Sobre esta cuestión, véase: Gambarotto, Andrea, Vital Forces, Teleology and Organization. Philosophy of Nature and the Rise of Biology in Germany, Dordrecht, Springer, 2018, pp. 11-13.

35 Un ejemplo de esta percepción (que anuda darwinismo y liberalismo como objetos de crítica), se encuentra en Cartas biológicas a una dama (1920), donde Uexküll plantea: “¿es verdaderamente apta la época actual para buscar en la conformidad a plan la esencia de lo viviente? Vivimos dentro de un Estado que se encuentra en putrefacción total. Dentro y fuera de la patria se impone la infamia desvergonzada y ésta amenaza con destruir todo el patrimonio cultural" (Uexküll, Jacob von, Cartas biológicas a una dama, Buenos Aires, Cactus, 2014, pp. 157-158).
} 
Frente al vitalismo filosófico y, en particular, frente a Simmel, Uexküll va a sostener que la vida no es un impulso auto-trascendente, ella misma es trascendental. Para él, la antinomia entre la vida y las formas es un falso problema. La verdadera cuestión, desde su perspectiva, es demostrar que hay fenómenos irreductibles al monismo materialista y a cualquier variante evolucionista filogenética. Contra la visión mecanicista y fisicalista del mundo, Uexküll afirma que tanto la vida cuanto las formas son factores supramecánicos, es decir, fenómenos que no se pueden explicar mediante un concepto de causalidad antecedente. Más aún, para él, "Vida igual a Forma"36: son vitales las estructuras, son vitales las reglas, lo maravillosamente vital es el orden que manifiesta la naturaleza, y no alguna finalidad o fuerza autotrascendente. Dicho en otros términos, el estructuralismo de Uexküll es vitalista porque hace de las relaciones sistemáticas entre partes, hace de las formas y de los sistemas de relaciones inmateriales que ellas entrañan, las más altas manifestaciones de la autonomía de la vida. Para él, el problema es el materialismo y el mecanicismo físico-químico, no las formas. Las formas son la vida y no un obstáculo a ser rebasado. De este posicionamiento, afirmado en el concepto de conformidad a plan, se desprenden una serie de tesis correlativas: hay estructuras, no azar; hay reglas, no arbitrariedad; hay adecuación y ajuste, no adaptación; hay relaciones inmateriales, no puras causas; hay autonomía, no heteronomía; hay objetividad, no variación.

Con este movimiento teórico-metodológico Uexküll esboza un nuevo campo de objetividad para la biología, donde "objetivo" no es sinónimo de método analítico y causal, sino campo teórico en donde se captan conceptualmente sistemas de relaciones, estructuras, leyes de articulación y reglas fijas. Para él, nadie que haga del azar y la contingencia factores de creación de formas vitales puede llamarse a sí mismo científico y, como diría otro pensador notable, la naturaleza no juega a los dados.

Desde este horizonte, Uexküll plantea que la tarea de la biología anida en reconstruir reflexiva y teóricamente el orden del que dan fe los fenómenos vitales en sus manifestaciones espaciales, y en la lógica reglada que revelan sus procesos temporales. De allí que el objeto principal de la investigación biológica sean los planos de construcción o tipos de estructura de cada animal, los Bauplan específicos. ¿Qué son estos? "no una cosa material, sino, más bien,

${ }^{36}$ Jacob von Uexküll, Teoría de la vida, p. 50. 
una unidad de la relación inmaterial que existe entre las diferentes partes de un cuerpo animal". ${ }^{37}$ Es decir, se trata de investigar la forma de los vivientes, no sus componentes materiales o su funcionamiento energético. Uexküll pone como ejemplo de procedimiento análogo a la estereometría, que busca representar geométricamente los cuerpos de tres dimensiones en función de las relaciones inmateriales que entrañan y que los definen. En este marco, y dando cuenta del suelo histórico-epistemológico del que es parte, Uexküll señala: "Cuando a mediados del siglo pasado se redujo la totalidad de los fenómenos a los dos factores de fuerza y materia, se pasó por alto un tercer factor, es decir, la forma". 38

¿Cuál es la especificidad del estructuralismo vitalista uexkülliano? A diferencia de la "finalidad dinámica" que defiende Driesch, Uexküll afirma que su enfoque remite a una "finalidad estática", y que hay que distinguir cuidadosamente las ideas de "tendencia a un fin" y de "conformidad a plan". 39 Mientras que la primera presupone un obrar psicológico y, en cierto modo, la acción del futuro sobre el presente, la segunda aparece como un concepto regulativo, como un juicio reflexionante, que ha de guiar la investigación experimental de los fenómenos. Uexküll independiza así el concepto de totalidad con respecto al de finalidad, y espacializa a la teleología tematizando "un fin no temporal". ${ }^{40}$ En este sentido, plantea:

la conformidad a plan sólo es dada en la intuición espacial. En eso se diferencia de la tendencia a un fin, la cual añade el tiempo como ulterior factor. Nosotros sólo podemos comprender aquellas máquinas cuyas ruedas están puestas unas a lado de otras en el espacio; máquinas cuyas ruedas están parte en el porvenir y parte en el pasado son para nosotros totalmente incomprensibles. ${ }^{41}$

Esta metáfora no debe confundirnos, Uexküll comparte con Driesch que la vida es un fenómeno supra-mecánico y ello por varias razones. La primera es tradicional: ninguna máquina se construye, se repara y se gobierna a

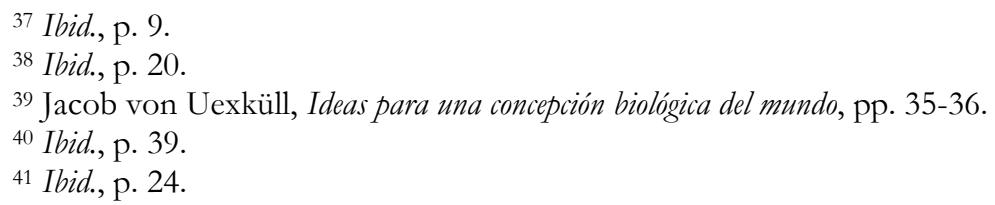


sí misma; y los vivientes se muestran como seres autónomos, no heterónomos. La segunda razón es la insuficiencia del concepto mecanicista de causalidad para explicar el desarrollo y el comportamiento de los seres vivientes. Dicho concepto, señala Uexküll, "conoce simplemente el efecto de lo antecedente sobre lo siguiente en el tiempo; pero jamás la reacción de lo siguiente en el tiempo sobre lo antecedente. Pero esta retroacción existe siempre si concebimos toda la existencia como una unidad dada". ${ }^{42}$ Este hecho es notable pues nos permite advertir que, varias décadas antes de que emerja el concepto cibernético de retroalimentación, Uexküll pone en juego una idea de causalidad circular que, con respecto a la física newtoniana, es claramente supra-mecánico (esta intuición eidética llegará a puerto en 1919-1920, con la formulación del concepto de círculo funcional [Funktionskreis]).

La tercera razón anida en que, si bien la investigación uexkülliana principia con un abordaje fisiológico donde la analogía con la máquina tiene alguna utilidad para pensar funcionamientos reflejos, el uso que se le dará a dicha analogía será netamente anti-mecanicista, es decir, se empleará fundamentalmente para marcar diferencias y no identidades. Uexküll ilustra esta perspectiva cuando afirma: "Del mismo modo que el técnico se interesa por el plan heterónomo de estructuración de nuestras máquinas, el biólogo se interesa en primer lugar por el plan autónomo de estructuración de los organismos". 43

Desde mediados de la década de 1910, con la profundización del pasaje desde la fisiología a la biología teórica, el enfoque estructural uexkülliano no solo tematizará el plano de construcción (Bauplan) de cada animal específico, sino también el conjunto de relaciones inmateriales que lo atan a su medio asociado (Umwelt). He aquí una de las principales originalidades de Uexküll: el carácter organizado de los seres vivientes no remite solo a la correlación de sus órganos y a su armónica estructura anatómica (hecho ya señalado por la tradición vitalista desde fines del siglo XVIII), sino también al conjunto de relaciones que entablan con el medio, es decir, a vínculos de orden etológicoecológico. Y en estos vínculos, agrega, no hay una mezcla de azar y necesidad, no hay heteronomía ni improvisación, sino regímenes de percepción

\footnotetext{
${ }^{42}$ Ibid., p. 39.

${ }^{43}$ Jacob von Uexküll, Teoría de la vida, p. 28.
} 
específicos y ritmos operatorios precisos. ${ }^{44}$ En este sentido, para Uexküll, los animales no son máquinas gobernadas por tropismos (como sostenía Jacques Loeb), y tampoco aprenden a comportarse por un proceso de ensayo y error (como planteaba Herbert Spencer Jennings), son sujetos autónomos que se desempeñan conforme a reglas y leyes, están dotados de facultades perceptivas y efectoras específicas y, en tanto viven, no se adaptan a un medio hostil sino que constituyen su propio mundo circundante (Umwelt).

En su último libro, Teoría de la significación (1940), Uexküll extenderá el influjo de su enfoque estructural y lo aplicará, no a los animales como formas y tampoco a sus mundos circundantes específicos, sino a la naturaleza toda como sistema de relaciones significantes. En este sentido, se focalizará en pensar las relaciones de significación que enlazan animales y/o mundos circundantes heterogéneos en función de un plan general, de una partitura de la Naturaleza, que explicaría desde un horizonte estructural la articulación entre especies diversas en términos de relaciones de punto y contrapunto. ${ }^{45}$ Es decir, el problema ya no será formalizar el carácter ordenado de un animal como unidad funcional (Bauplan), ni reconstruir su relación conforme a plan con un conjunto de portadores de significado específicos (Umwelt), sino tematizar cuál es el vínculo que articula seres heterogéneos, esto es, cuál es el código que habilita que la garrapata y el mamífero, o el murciélago y la mariposa, o la mosca y la araña, puedan ser elementos de un proceso de significación que los engloba. Uexküll denomina "técnica de la Naturaleza" a esta nueva efectuación de su enfoque estructural y concluye que, desde esta perspectiva, la tarea "de la biología sería la de escribir la partitura de la Naturaleza". ${ }^{46}$

\footnotetext{
44 Uexküll sintetiza esta ampliación del enfoque estructural cuando indica: "Toda ley técnica no alude meramente a las relaciones regulares de las partes entre sí, sino que aparece en relaciones regulares con ciertos factores del mundo exterior" (Jacob von Uexküll, Cartas biológicas a una dama, p. 144).

45 “Cubierta por la cortina de los fenómenos se realiza la unión de los diferentes arquetipos o melodías primitivas con arreglo a un extenso plan de significación. (...) La significación es el norte hacia el cual tiene que dirigirse la Biología, y no la mezquina regla de causalidad, la cual no puede ver más allá de un paso hacia adelante y otro hacia atrás, pero a la que las grandes correlaciones permanecen totalmente ocultas" (Uexküll, Jacob von, Meditaciones biológicas. La teoría de la significación, Madrid, Revista de Occidente, 1942, pp. 63-64).

46 Ibid., p. 126.
} 
Si recapitulamos lo dicho hasta aquí podemos advertir que el estructuralismo vitalista de Uexküll se expresa en una "teleología estática" que, a través de la observación experimental y el concepto de "conformidad a plan", reconstruye relaciones inmateriales que definen distintos órdenes formales a nivel fisiológico (Bauplan), etológico (Umwelt) y ecológico (la Naturaleza como sistema de significaciones trans-específicas). Llegados a este punto cabe preguntarse cómo se efectúa el enfoque uexkülliano no ya en relaciones espaciales y estructurales, sino en procesos temporales y genéticos. En efecto, ¿cómo pensar fenómenos en los cuales los elementos no están dados uno al lado de otro en una configuración actual, sino que se despliegan en función de órdenes de sucesión? En principio, como hemos visto, Uexküll aparta por insoluble el problema filogenético y se concentra en la ontogénesis, esto es, en los procesos de formación y desarrollo de los individuos vivientes, dinámicas que suponen un "plan de origen" y un "plan de tiempo". ${ }^{47}$

Contra el preformacionismo fijista de los siglos XVII y XVIII (que suponía la existencia de una estructura netamente diferenciada en el germen que no haría más que crecer en magnitud), Uexküll reivindica la embriología de Karl E. von Baer, pues considera que demuestra que el desarrollo del embrión es un proceso de estructuración riguroso, que se desenvuelve siguiendo un estricto orden de sucesión y que, por ello, da cuenta de la existencia "un factor natural independiente, que posee su propia ley, que es precisamente la conformidad a plan". 48

Con lo cual, las formas no son necesariamente espaciales, sino que también pueden ser pensadas en su desarrollo temporal, esto es, como patrones regulares que se encuentran estructurados en secuencias y en fases. Estas formas, sin embargo, ordenan una secuencia de movimientos de acuerdo con un "fin no temporal" y, en este sentido, suponen una subordinación del orden de la sucesión al orden de la simultaneidad. Así como la ejecución de toda melodía supone una partitura, todo proceso temporal -sea genético o dinámico- se desenvuelve conforme a un plan inmanente y autónomo, que proporciona un orden y un sentido al devenir.

Con este movimiento, Uexküll está en las antípodas de Bergson y de Simmel, quienes se valían del devenir temporal para pensar el carácter creador

${ }^{47}$ Jacob von Uexküll, Ideas para una concepción biológica del mundo, p. 140.

${ }^{48}$ Ibid., p. 126. 
y abierto de la vida frente a las formas. Uexküll reconoce que a nivel de la dinámica del comportamiento individual operan elementos de variabilidad (por ejemplo, en las acciones basadas en la experiencia), pero rechaza que dichas variaciones afecten la estructura conforme a plan de la especie y que puedan ser pensadas como trascendiendo, o rebasando, la forma vital. Por el contrario, si hay animales superiores que poseen un margen de variabilidad y tienen la facultad de autogenerar en el devenir esquemas de función suplementarios, y funcionamientos diferenciales, ello es gracias a su estructura a priori y no contra ella.

Un último elemento de valor para ponderar el estructuralismo vitalista uexkülliano es la interpretación que propone de la genética de Gregor Mendel. Por un lado, se vale de ella para repensar el proceso embriológico y plantea que, en el desarrollo del embrión, tiene lugar una "melodía de formación" que, siguiendo un plan, afecta al protoplasma conforme una "secuencia de impulsos" (Impulsfolge). ¿Qué son los impulsos? Uexküll responde: son los genes, entidades descubiertas por Mendel y bautizadas como tales por Johannson. ${ }^{49}$ ¿Qué serían los genes? Predisposiciones de propiedades, tendencias a tener tal o cual propiedad. Una determinada composición formal de genes da lugar a un genotipo, y cada especie tiene su genotipo característico. Con lo cual, según Uexküll, los genes son impulsos y los genotipos "secuencias de impulsos", planos de formación que indican "la dependencia de los genes en el tiempo"..$^{50}$ Desde esta perspectiva, en la formación, los impulsos invaden el protoplasma activando a las células embrionarias y, siguiendo un orden, dan lugar a procesos de estructuración en los cuales los genes "entran en funcionamiento como impulsos genéticos de las leyes técnicas". ${ }^{51}$ Lo que resulta notable en esta representación es que lo más fijo es lo más vital, y la idea de impulso (de claras resonancias bergsonianas) se ve así reconducida a una superposición con la idea de gen (y los genes, según Uexküll, tienen dos propiedades fundamentales: la persistencia y la autonomía)..$^{52}$ Esta lectura se confirma, por otro lado, con la interpretación del problema de la herencia.

\footnotetext{
${ }^{49}$ Uexküll, Jacob von, Theoretical Biology, London, Kegan Paul/Trench, Trübner and Co, 1926, pp. 183, 198.

${ }^{50} \mathrm{Jacob}$ von Uexküll, Ideas para una concepción biológica del mundo, p. 139.

51 Jacob von Uexküll, Cartas biológicas a una dama, p. 144.

52 Jacob von Uexküll, Ideas para una concepción biológica del mundo, p. 138.
} 
Según Uexküll, Mendel refuta la teoría mecanicista-darwinista de la herencia porque demuestra que en ésta rigen proporciones y cantidades matemáticas fijas ${ }^{53}$, lo cual para él es una prueba más de la conformidad a plan de la naturaleza, de la inadecuación de los modelos evolucionistas-gradualistas filogenéticos, y de la validez de la ecuación "Vida igual a Forma".

\section{A modo de conclusión}

¿Qué significado extraer de la teoría uexkülliana? ¿Cuál sería la singularidad de su estructuralismo vitalista? Si se adoptase un punto de vista de historia social, o de sociología del conocimiento, la significación del enfoque de Uexküll podría reducirse a una mera reacción conservadora, a un llamado al orden en un contexto signado por conflictos sociales y crisis políticas. Esta es la tendencia de trabajos como el de Anne Harrington (1996), quien subraya el carácter de derecha del pensamiento uexkülliano. En favor de este argumento hay que decir que, indudablemente, Uexküll participa de una cosmovisión antiliberal y anti-comunista y, por otra parte, que retoma la máxima "Vida igual a Forma" del pensador conservador Houston Stewart Chamberlain, quien además fuera su amigo personal. Por otro lado, si se adoptase el punto de vista del desarrollo de la biología en el siglo XX, y se atendiese al triunfo de la teoría (neo)darwinista de la selección natural, la teoría de Uexküll no sería más que una mera reacción anti-moderna, nostálgica y tradicionalista, que en algunos aspectos recaería en elementos propios de la antigua teología natural. Este argumento es muy discutible pues, como hemos visto, el anti-darwinismo de Uexküll se emplaza en condiciones histórico-epistemológicas precisas y, por otra parte, su teoría aporta valiosos conceptos que han resultado fundantes para la etología y para la biosemiótica, al tiempo que han contribuido al desarrollo de perspectivas ecológicas.

Por nuestra parte, creemos que, desde un punto de vista históricoconceptual, el estructuralismo vitalista de Uexküll no es reducible a una reacción conservadora y anti-moderna. Por el contrario, acredita una singular significación y resulta un índice fructífero para pensar la descomposición del vitalismo filosófico de principios del siglo $\mathrm{XX}$, y la emergencia de nuevos conceptos en la filosofía continental. En este sentido, si se atiende al abandono

${ }^{53}$ Ibid., pp. 224-229. 
de las filosofías de la vida que se registra desde fines de la década de 1920 en pensadores como Max Scheler, Heidegger y Cassirer, y a la correlativa refocalización del problema antropológico en términos post-vitales, es posible pensar el estructuralismo vitalista uexkülliano como punto de bifurcación. De allí la importancia que, en este trabajo, asignamos a la ecuación Vida=Forma frente a la antinomia formas/vida que se plantea en filósofos como Bergson y Simmel. Con Uexküll, la idea según la cual la vida sería un impulso creador, o un elemento metafísico de auto-trascendencia de las formas, se vacía de sentido. El impacto del concepto uexkülliano de mundo circundante (Umwelt) en la filosofía alemana del período es indicativo al respecto. Síntoma de ello es que el sistema subjetivo-objetivo cerrado que dicho concepto pone de manifiesto (y que efectúa el principio Vida=Forma en el plano del comportamiento animal), oficia como bisagra en no pocas tesis de antropología filosófica. Esto se registra en Max Scheler (quien afirma que "lo que hace del hombre un hombre es un principio que se opone a toda vida en general" y que, por ello, el comportamiento humano "puede consistir en 'abrirse al mundo' en medida ilimitada") 54 , en Heidegger (que, frente a la "pobreza de mundo" del animal, destaca el carácter "configurador de mundo" del ser humano) $)^{55}$ y en Cassirer (para quien, a diferencia del resto de los animales, en el ser humano hay un "sistema simbólico" que media entre el sistema receptor y el efector, y que lo sitúa en "una nueva dimensión de la realidad").56

\section{Referencias bibliográficas}

- Agamben, Giorgio, Lo abierto, traducción de F. Costa y E. Castro, Buenos Aires, Adriana Hidalgo, 2006.

- Alsina Calvés, José, "La biología en Los conceptos fundamentales de la metafísica de Martin Heidegger: influencias de Hans Driesch y de Jakob von Uexküll", Filosofia e História da Biologia, vol. 13, 1 (2018), [61-70].

\footnotetext{
${ }^{54}$ Scheler, Max, Elpuesto del hombre en el cosmos, Buenos Aires, Losada, 2003, pp. 60, 64.

55 Heidegger, Martin, Conceptos fundamentales de metafísica. Mundo, finitud, soledad (19291930), Madrid, Alianza, 2007, pp. 223 y ss.

${ }^{56}$ Cassirer, Ernst, Antropología filosófica, México, Fondo de Cultura Económica, 2009, p. 47.
} 
- Araújo, Arthur, "Structure, sign and Uexküll's theory of meaning: A philosophical approximation”, Cognitio, vol. 17, 1 (2016), [13-38].

- Bacarlett Pérez, María Luisa, "Uexküll y Merleau-Ponty: una ontología del entre", Metatheoria, vol. 5, 1 (2014), [35-47].

- Bergson, Henri, La evolución creadora, traducción de M. L. Pérez Torres, Barcelona, Planeta, 1985.

- Bertalanffy, Ludwig von, Teoría general de los sistemas, traducción de J. Almela, México, Fondo de Cultura Económica, 1989.

- Brentari, Carlo, "How to make worlds with signs. Some remarks on Jacob von Uexküll's Umwelt theory", Rivista Italiana di Filosofia del Linguaggio, vol. 7, 2 (2013), pp. 8-21. DOI 10.4396/20130701

- Brentari, Carlo, Jakob von Uexküll - The discovery of the Umwelt between Biosemiotics and Theoretical Biology, Dordrecht, Springer, 2015.

- Buchanan, Brett, Onto-Ethologies. The Animal Environments of Uexküll, Heidegger, Merleau-Ponty and Deleuze, Albany, State University of New York Press, 2008.

- Cassirer, Ernst, Las ciencias de la cultura, traducción de W. Roces, México, Fondo de Cultura Económica, 1975.

- Cassirer, Ernst, El problema del conocimiento IV, traducción de W. Roces, México, Fondo de Cultura Económica, 1998.

- Cassirer, Ernst, Antropología filosófica, traducción de E. Ímaz, México, Fondo de Cultura Económica, 2009.

- Castro García, Óscar, El concepto de Umwelty el origen de la biosemiótica, Barcelona, Tesis de doctorado (Universidad de Barcelona), 2009.

- Chien, Jui-Pi, "Of Animals and Men: A Study of Umwelt in Uexküll, Cassirer, and Heidegger", Concentric: Literary and Cultural Studies, vol. 32, 1 (2006), pp. 5779 .

- Driesch, Hans, The history and theory of vitalism, London, MacMillan and Co, 1914.

- Gambarotto, Andrea, Vital Forces, Teleology and Organization. Philosophy of Nature and the Rise of Biology in Germany, Dordrecht, Springer, 2018. 
- Guidetti, Luca, "Jakob von Uexküll tra Kant e Leibniz. Dalla filosofia trascendentale alla topologia del viviente", Rivista Italiana di Filosofia del Linguaggio, vol. 7, 2 (2013), pp. 66-83.

- Harrington, Anne, Reenchanted Science: Holism in German Culture from Wilhelm II to Hitler, Princeton, Princeton University Press, 1996.

- Heidegger, Martin, Conceptos fundamentales de metafisica. Mundo, finitud, soledad (1929-1930), traducción de A. Ciria, Madrid, Alianza, 2007.

- Huxley, Julian, Evolution: The Modern Synthesis, London, George Allen and Unwin, 1948.

- Jankélévitch, Vladimir, Georg Simmel, filósofo de la vida, traducción de A. García Castro, Barcelona, Gedisa, 2007.

- Kull, Kalevi, “Jakob von Uexküll: An introduction”, Semiotica, 134 1/4 (2001), pp. 1-59.

- Kull, Kalevi, "Uexküll and the post-modern evolutionism", Sign Systems Studies, 32 1/2 (2004), pp. 99-114.

- Kull, Kalevi, Emmeche, Claus, Hoffmeyer, Jesper et al., "Theses on Biosemiotics: Prolegomena to a Theoretical Biology", Biological Theory, vol. 7, 2 (2009), pp. 167-173.

- Krois, John Michael, “Ernst Cassirer's philosophy of biology “, Sign Systems Studies, $32 \frac{1}{2}$ (2004), pp. 277-295.

- Mildenberger, Florian, Umwelt als Vision. Leben und Werk Jakob von Uexkülls (1866-1944), Stuttgart, Steiner, 2007.

- Muñoz Pérez, Enrique, "El Aporte de Jakob von Uexküll a Los conceptos fundamentales de la metafisica. Mundo, finitud, soledad (1929-1930) de Martin Heidegger”, Diánoia, vol. LX, 75 (2015), pp. 85-103.

- Olivé Pérez, Alfonso, La perspectiva filosófica y biológica de la noción orteguiana de "vida", Barcelona, Tesis de doctorado (Universidad de Barcelona), 2018.

- Ostachuk, Agustín, "El Umwelt de Uexküll y Merleau-Ponty", Ludus Vitalis, vol. XXI, 39 (2013), pp. 45-65. 
- Palti, Elías José, “El 'retorno del sujeto'. Subjetividad, historia y contingencia en el pensamiento moderno", Prismas. Revista de historia intelectual, 7 (2003), pp 27-50.

- Rüting, Torsten, "History and significance of Jakob von Uexküll and of his institute in Hamburg", Sign Systems Studies, 32 1/2 (2004), pp. 35-72.

- Scheler, Max, El puesto del hombre en el cosmos, traducción de J. Gaos, Buenos Aires, Losada, 2003.

- Simmel, Georg, El individuo y la libertad. Ensayos de crítica de la cultura, traducción de S. Mas, Barcelona, Península, 1998.

- Simmel, Georg, Intuición de la vida. Cuatro capitulos de metafísica, traducción de J. Rovira Armengol, La Plata, Caronte, 2004.

- Stjernfelt, Frederik, "Simple animals and complex biology: Von Uexküll's two-fold influence on Cassirer's philosophy", Synthese, vol. 179, 1 (2009), pp. 169-186. DOI: 10.1007/s11229-009-9634-5

- Uexküll, Jacob von, Theoretical Biology, traducción de D. L. Mackinnon, London, Kegan Paul/Trench, Trübner and Co, 1926.

- Uexküll, Jacob von, Meditaciones biológicas. La teoría de la significación, traducción de J. M. Sacristán, Madrid, Revista de Occidente, 1942.

- Uexküll, Jacob von, Teoría de la vida, s/trad., Madrid, Summa, 1944.

- Uexküll, Jacob von, Ideas para una concepción biológica del mundo, traducción de R.

M. Tenreiro, Buenos Aires, Espasa-Calpe, 1951.

- Uexküll, Jacob von, Cartas biológicas a una dama, traducción de T. Bartoletti y L. C. Nicolás, Buenos Aires, Cactus, 2014.

Recibido: 07/2019. Aceptado: 02/2020. 